\title{
Thermal Conductivity and Deformation of Taxodium Hybrid 'Zhongshanshan' during Heat Transfer Process
}

Yuehua Zhu, Yaoli Zhang, and Biao Pan*

\begin{abstract}
The thermal conductivity and the deformation of wood from the Taxodium hybrid 'Zhongshanshan' were studied in the process of heat transfer. The results showed that the average thermal conductivity of this wood was $0.1257 \mathrm{~W} /(\mathrm{m} \cdot \mathrm{K})$ under the condition of $12 \%$ wood moisture content and $30{ }^{\circ} \mathrm{C}$ heat transfer temperature. When the testing temperature exceeded $0{ }^{\circ} \mathrm{C}$, the thermal conductivity increased linearly with both temperature and wood moisture content and was affected by the moisture content of the wood. During the heat transfer process, the deformation of features caused repeated swelling and shrinkage in the longitudinal, radial, and tangential directions. The dimensional change was greatly affected by the wood's moisture content and was less affected by the temperature. These results are of great meaning for the study of the heat transfer process of Taxodium hybrid 'Zhongshanshan' wood. Furthermore, it provides a scientific basis for the heat preservation effect, drying treatment, and pyrolysis treatment of Taxodium hybrid 'Zhongshanshan' wood for use as a building material.
\end{abstract}

Keywords: Taxodium hybrid 'Zhongshanshan'; Thermal conductivity; Heat transfer temperature; Moisture content; Deformation

Contact information: College of Materials Science and Engineering, Nanjing Forestry University, Nanjing 210037, China; *Corresponding author: pan.biao@163.com

\section{INTRODUCTION}

Taxodium hybrid 'Zhongshanshan' is an excellent tree species and is cultivated by artificial hybridization at the Institute of Botany, Jiangsu Province and Chinese Academy of Sciences, Jiangsu, China. The following two species of the genus Taxodium (family: Cupressaceae), Taxodium mucronatum (salt-alkali tolerant) and Taxodium distichum (rapid growth and good stem form), were used to conduct interspecific hybridization experiments and to initiate the breeding of fast-growing, as well as salt and alkali tolerant varieties (Shi et al. 2016; Hua et al. 2017). In practice, Taxodium hybrid 'Zhongshanshan' wood is prone to deformation during drying, which increases the difficulty of the drying process. Therefore, it is necessary to study the heat transfer characteristics of Taxodium hybrid 'Zhongshanshan' wood in depth to realize its high-efficiency and high-quality in wood utilization.

Wood is a porous material. Heat transfer in wood is a combination of the heat transfer that simultaneously occurs in the solids, liquids, and gases that make up the cells of the wood tissue. Measuring the thermal conductivity is the main method to study the heat transfer characteristics of materials (Gu et al. 2005). Thermal conductivity is one of the intrinsic physical parameters of materials; this fact enables the characterization of the thermal conductivity of materials. Studying the heat transfer characteristics of wood is of 
great significance for heat preservation, drying, pyrolysis, and thermal conversion of wood components (Saastamoinen et al. 1996).

The thermal conductivity of porous materials can be defined based on the concept of an effective thermal conductivity (Thunman et al. 2002). Measuring the effective thermal conductivity of wood experimentally at the macroscopic level is an effective approach to obtain the heat transfer characteristics. Suleiman et al. (1999) investigated the influences of temperature, density, porosity, and anisotropy on the thermal conductivity of birch (Betula pendula). Sahin Kol (2009) studied the influence of wood moisture content on the thermal conductivity of pinewood (Pinus sylvestris) in the transverse direction and determined the relationship between thermal conductivity and dielectric parameters. Dundar et al. (2012) studied the relationship between thermal conductivity and both the physical and mechanical properties of wood and identified a significant linear relationship between thermal conductivity and density, bending strength, elastic modulus, and impact toughness.

The dominant method to measure the thermal conductivity is the steady-state plate method. When the wood absorbs thermal energy from the environment, the temperature of wood will increase. This increase in wood temperature will cause an increase of wood energy, which gives rise to a subsequent increase in the amplitude of the molecular vibration and the average distance between molecules. Eventually, the overall dimensions of wood increase, and the linear expansion, area expansion, or volumetric expansion of the wood is the result (Sasthiryar et al. 2014). For the steadystate flat test method, a temperature difference is required between both surfaces of wood specimens. When a temperature gradient exists within the wood, the thermal expansion will produce inner stress and cause deformation in the wood.

Based on previous studies, in this work a steady-state flat plate thermal conductivity meter was employed to accurately determine the thermal conductivity of Taxodium hybrid 'Zhongshanshan' wood. Dimensional changes of wood during the process of heat transfer were recorded by a strain gauge and static data acquisition meter to study the occurrence of wood deformation during the heat transfer process. This study has important significance for the study of the heat transfer process of Taxodium hybrid 'Zhongshanshan' wood and provides a scientific basis for the heat preservation effect, drying treatment, and pyrolysis treatment of Taxodium hybrid 'Zhongshanshan' wood as a building material.

\section{EXPERIMENTAL}

\section{Materials}

Taxodium hybrid 'Zhongshanshan' wood was obtained from the Garden and Seedling Experimental Demonstration Base of the Institute of Botany, Jiangsu Province and Chinese Academy of Sciences (Liuhe District, Nanjing City, Jiangsu Province, China). The average basic density of the wood was $0.314 \mathrm{~g} / \mathrm{cm}^{3}$. Radial and tangential wood boards having a minimum or defects were selected from air-dried heartwood and sapwood. According to the specimen requirements of the heat conductivity meter, the above four types of wood boards were cut into wood specimens with dimensions of 210 $\mathrm{mm}$ length, $210 \mathrm{~mm}$ width, and $30 \mathrm{~mm}$ height. Three specimens were prepared for each type of wood board, and therefore, a total of 12 specimens were prepared. The wood specimens were sanded with 240-grit sandpaper for testing. The radial and tangential 
heartwood specimens were respectively marked as HR and HT, while the radial and tangential wood specimens of sapwood were respectively marked as SR and ST. Subsets of the SR and ST specimens were soaked in distilled water for 12 and $24 \mathrm{~h}$, respectively, to increase the moisture content. The treatment conditions of each group of specimens before thermal conductivity testing are shown in Table 1.

\section{Table 1. Treatment Conditions of Each Group Specimens before Thermal Conductivity Testing}

\begin{tabular}{|c|c|}
\hline Specimen & Treatment Condition \\
\cline { 1 - 1 } HR & Air-dried \\
\cline { 1 - 1 } HT & \\
\hline SR & \\
\hline ST & Soaked in distilled water for $12 \mathrm{~h}$ \\
\hline SR & Soaked in distilled water for $24 \mathrm{~h}$ \\
\hline ST & \\
\hline
\end{tabular}

\section{Methods}

Measurement of wood moisture content

The mass of the specimens $\left(W_{n}\right)$ was recorded before and after the thermal conductivity measurement. After the thermal conductivity measurement, the specimens were dried in an oven at $103{ }^{\circ} \mathrm{C} \pm 2{ }^{\circ} \mathrm{C}$ until constant weights were obtained, and the oven-dried weights were recorded as $W_{0}$. The wood moisture content $(M)$ at each stage of the drying process was calculated using Eq. 1,

$$
M(\%)=\frac{W \mathrm{n}-W 0}{W 0} \times 100
$$

where $W_{\mathrm{n}}$ represents the wood mass $(\mathrm{g})$ at each stage of drying process and $W_{0}$ represents the mass $(\mathrm{g})$ of oven-dried wood.

\section{Measurement of thermal conductivity}

The thermal conductivity of wood specimens was measured with an EKO HC-074 200 thermal conductivity measuring instrument (EKO Instruments Co., Ltd., Tokyo, Japan) and was operated according to the ASTM C518-17 (2017) standard.

Figure 1 shows the mechanism for the thermal conductivity testing. The testing specimen with thickness $d$ and length $D$ is sandwiched between two plates and heat is transferred from the lower hot plate to the upper cold plate through the testing specimen. When the temperatures of both hot and cold plates are steady, a temperature gradient within the testing specimen is generated due to the temperature differences between the plates. Thus, the thermal conductivity can be obtained. According to the Fourier heat conduction equation, the thermal conductivity $\lambda$ of the single-layer flat specimen in thickness direction can be calculated according to Eq. 2,

$$
\lambda=\frac{Q d}{D^{2}\left(T_{1}-T_{2}\right)}
$$

where $\lambda$ represents the thermal conductivity $[\mathrm{W} /(\mathrm{m} \bullet \mathrm{K})], Q$ represents the quantity $(\mathrm{J})$ of heat passing through the area $D^{2}$ from the plate with high temperature to the plate with low temperature in the testing specimen, $d$ represents the thickness $(\mathrm{m})$ of the testing specimen, $D$ represents the side length (m) of the testing specimen, $T_{1}$ represents the temperature $\left({ }^{\circ} \mathrm{C}\right)$ of the hot plate, and $T_{2}$ represents the temperature $\left({ }^{\circ} \mathrm{C}\right)$ of the cold plate. 


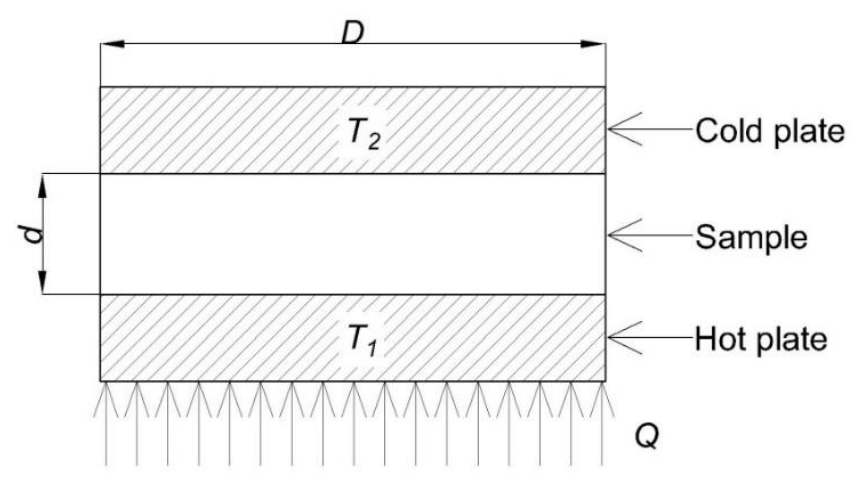

Fig. 1. Mechanism of thermal conductivity testing

In this experiment, the temperatures of both the cold and hot plates were separated into five groups as shown in Table 2.

Table 2. Test Temperature Setting

\begin{tabular}{|c|c|c|c|c|}
\hline $\begin{array}{c}\text { Temperature } \\
\text { Setting }\end{array}$ & $\begin{array}{c}T_{1} \\
\left({ }^{\circ} \mathrm{C}\right)\end{array}$ & $\begin{array}{c}T_{2} \\
\left({ }^{\circ} \mathrm{C}\right)\end{array}$ & $\begin{array}{c}\text { Testing Temperature } \\
\left({ }^{\circ} \mathrm{C}\right)\end{array}$ & $\begin{array}{c}\text { Heat Transfer Temperature } \\
\left({ }^{\circ} \mathrm{C}\right)\end{array}$ \\
\hline Test 1 & 0 & -20 & -10 to 0 & 0 \\
\hline Test 2 & 20 & 0 & 0 to 10 & 10 \\
\hline Test 3 & 40 & 20 & 10 to 30 & 30 \\
\hline Test 4 & 60 & 40 & 30 to 50 & 50 \\
\hline Test 5 & 80 & 60 & 50 to 70 & 70 \\
\hline
\end{tabular}

The testing temperature is the temperature of the testing specimen before the cold and hot plates of the instrument reached a constant temperature during the testing. The heat transfer temperature is the temperature of the testing specimen when the cold and hot plates of the instrument reached a constant temperature during the testing.

\section{Measurement of dimensional changes}

The lengths of the specimens in the longitudinal, radial, and tangential directions before and after thermal conductivity testing were measured by Vernier calipers. The deformation degree $(D)$ of the specimens in the longitudinal, radial, and tangential directions at each stage was calculated according to Eq. 3,

$$
D(\%)=\frac{\left(D_{n}-D_{0}\right)}{S_{0}} \times 100
$$

where $D_{\mathrm{n}}$ represents the length $(\mathrm{mm})$ of the wood specimen at each stage and $D_{0}$ represents the initial length $(\mathrm{mm})$ of wood specimen.

The specimen group HT was selected for the test and was arranged with the strain gauge in the longitudinal, radial, and tangential directions. The strain gauge was applied with a neutral resin glue to prevent the influence of humidity and temperature on the strain gauge. While measuring the thermal conductivity, the dimensional changes of the specimens in longitudinal, radial, and tangential directions were recorded at an interval of $30 \mathrm{~s}$ by a TDS-530 static data acquisition meter (TML Co., Ltd., Tokyo, Japan). 


\section{RESULTS AND DISCUSSION}

\section{Change in Moisture Content of Air-dried Specimens}

When the steady-state plate method was used to measure the thermal conductivity, the instrument required a long time to achieve thermal stability between the cold and hot plates. During this period, the moisture content of the wood changed. Table 3 shows the average moisture content of the air-dried testing specimen after thermal conductivity testing at five different temperature settings.

Table 3. Average Moisture Content of Air-dried Specimens

\begin{tabular}{|c|c|c|c|c|}
\hline Testing Temperature $\left({ }^{\circ} \mathrm{C}\right)$ & $\begin{array}{c}\text { HR Average } \\
\text { MC (\%) }\end{array}$ & $\begin{array}{c}\text { HT Average } \\
\text { MC (\%) }\end{array}$ & $\begin{array}{c}\text { SR Average } \\
\text { MC (\%) }\end{array}$ & $\begin{array}{c}\text { ST Average } \\
\text { MC (\%) }\end{array}$ \\
\hline Environmental temperature 28 & 12.43 & 12.52 & 12.61 & 13.18 \\
\hline-10 to 0 & 14.53 & 14.75 & 16.42 & 14.37 \\
\hline 0 to 10 & 13.04 & 13.38 & 12.70 & 13.66 \\
\hline 10 to 30 & 12.74 & 13.24 & 12.67 & 13.19 \\
\hline 30 to 50 & 12.58 & 13.21 & 12.64 & 13.25 \\
\hline 50 to 70 & 11.25 & 12.64 & 11.92 & 12.78 \\
\hline
\end{tabular}

Table 3 shows that the moisture content of the air-dried wood specimens increased as the temperature was decreased from room temperature to $-10{ }^{\circ} \mathrm{C}$ and then it was increased to $0{ }^{\circ} \mathrm{C}$. This was because during testing, the temperature of the cold plate decreased below $0{ }^{\circ} \mathrm{C}$, and the solidification of water vapor in the air impelled the moisture to penetrate the testing specimen, thus resulting in an increased moisture content of the testing specimen at low temperatures. During subsequent testing, the wood moisture content changed slightly when the testing temperature increased from $0{ }^{\circ} \mathrm{C}$ to $50{ }^{\circ} \mathrm{C}$ while it began to decrease when the testing temperature increased from $50{ }^{\circ} \mathrm{C}$ to $70{ }^{\circ} \mathrm{C}$. When the environment temperature rises from $0{ }^{\circ} \mathrm{C}$ to $50{ }^{\circ} \mathrm{C}$, temperature causes water evaporation and moisture content decreases. Water evaporation is related to ambient temperature. The higher the temperature, the faster the water evaporates. When the environment temperature rises from $50{ }^{\circ} \mathrm{C}$ to $70{ }^{\circ} \mathrm{C}$ Water evaporation accelerates, and the moisture content decreases rapidly.

\section{Thermal Conductivity of Taxodium Hybrid 'Zhongshanshan' Wood}

Figure 2 shows the change of thermal conductivity of the air-dried specimens. In general, the thermal conductivity of wood is independent of its source (i.e., heartwood or sapwood) and is related to its direction (i.e., radial or tangential) (Maclean 1941; Gu et al. 2006). The results obtained in this study largely conform to the above conclusion, except that when the testing temperature was increased from $-10{ }^{\circ} \mathrm{C}$ to $10{ }^{\circ} \mathrm{C}$, the thermal conductivity of the radial heartwood specimens was remarkably lower than that of radial sapwood specimens. This was attributed to the lower moisture content of radial heartwood specimens compared with radial sapwood specimens, which is shown in Table 2. 


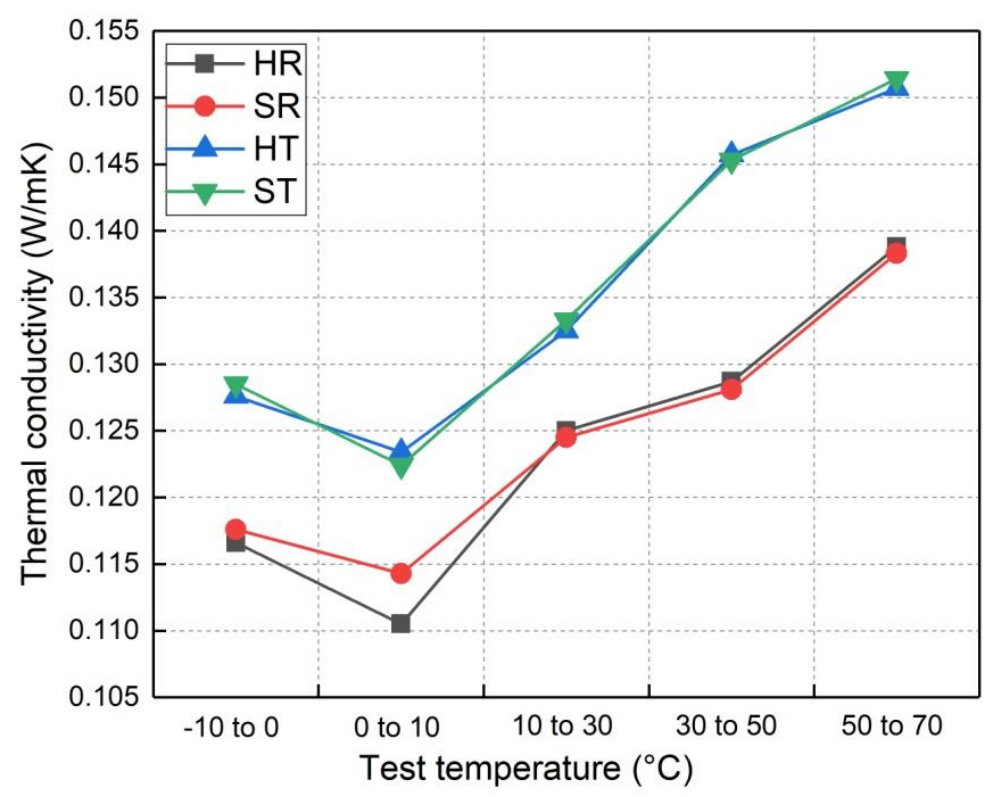

Fig. 2. Thermal conductivity of Taxodium hybrid 'Zhongshanshan' wood

For major wood species, the radial direction shows varying degrees of larger thermal conductivity compared with the tangential direction. However, in this study, the thermal conductivity in radial direction was smaller than that of the tangential direction. The ratio of the radial thermal conductivity to the tangential thermal conductivity depends on the cell volume of the wood rays and the density of the earlywood and latewood (Steinhage 1977). Taxodium hybrid 'Zhongshanshan' is a fast-growing species. Its earlywood tracheid has thin cell walls and large cell cavities, while its latewood tracheid has thick cell walls and small cell cavities. As a result, the latewood has a remarkably higher density than the earlywood and the volume ratio of the wood ray is small. According to a previous study, the radial dimension of the earlywood tracheid is larger than the tangential dimension (Zhu et al. 2019). Thus, the proportion of heat flow passing through the gap is higher in the radial direction than in tangential direction. In addition, the thermal conductivity of the air in the gap is much lower than that of the solid material of the wood. Therefore, most of the heat transmitted along the tangential dimension in latewood has low thermal resistance, resulting in a larger tangential thermal conductivity than the radial thermal conductivity. The ratio of the tangential thermal conductivity to the radial thermal conductivity of the Taxodium hybrid 'Zhongshanshan' wood was in the range 1.07 to 1.09 .

\section{Effect of Temperature and Wood Moisture Content on Thermal Conductivity}

Figure 2 shows the effect of temperature on the thermal conductivity. When the testing temperature was increased from $-10{ }^{\circ} \mathrm{C}$ to $10{ }^{\circ} \mathrm{C}$, the thermal conductivity decreased. Because the temperature of the cold plate was lower than $0{ }^{\circ} \mathrm{C}$, during the heating process, heat flow was transmitted from the hot plate to the cold plate. Thus, the ice on the cold plate partially absorbed this heat and melted into water. Consequently, the conduction heat loss of the testing specimens increased, causing a decrease in the thermal conductivity with increasing temperature. During the period when the temperature was increased above $10{ }^{\circ} \mathrm{C}$, the thermal conductivity increased with increasing testing temperature. This increased temperature intensified the thermal motion of water and air 
molecules in the pores of the wood and enhanced the thermal radiation energy between the pore walls, thus resulting in increased thermal conductivity.

Table 4. Effect of Moisture Content on Thermal Conductivity

\begin{tabular}{|c|c|c|c|c|c|}
\hline \multirow{2}{*}{ Specimen } & $\begin{array}{c}\text { Moisture } \\
\text { Content } \\
(\%)\end{array}$ & $\begin{array}{c}\text { Thermal Conductivity } \\
(\mathrm{W} /(\mathrm{m} \cdot \mathrm{K}))\end{array}$ & \multirow{2}{*}{ Specimen } & $\begin{array}{c}\text { Moisture } \\
\text { Content } \\
(\%)\end{array}$ & $\begin{array}{c}\text { Thermal } \\
\text { Conductivity } \\
(\mathrm{W} /(\mathrm{m} \cdot \mathrm{K}))\end{array}$ \\
\cline { 5 - 5 } & $30^{\circ} \mathrm{C}$ & & & $30^{\circ} \mathrm{C}$ \\
\hline SR1 & 12.67 & 0.1333 & ST1 & 13.14 & 0.1245 \\
\hline SR2 & 12.67 & 0.1334 & HT3 & 13.18 & 0.1246 \\
\hline HR3 & 12.69 & 0.1334 & HT1 & 13.24 & 0.1250 \\
\hline HR1 & 12.73 & 0.1337 & ST2 & 13.24 & 0.1247 \\
\hline HR2 & 12.79 & 0.1338 & HT2 & 13.31 & 0.1253 \\
\hline SR3 & 52.33 & 0.2025 & ST3 & 78.17 & 0.1915 \\
\hline
\end{tabular}

Table 4 shows the relationship between moisture content and thermal conductivity of the wood. When the heat transfer temperature was $30{ }^{\circ} \mathrm{C}$, the thermal conductivity of heartwood and sapwood with different initial moisture contents increased with increasing moisture content. The thermal conductivity of water is approximately 23 times of that of air ( $\mathrm{Gu}$ et al. 2007). Wood is a porous material composed of solids and pores. With increasing moisture content of wood, the air inside the pores is replaced by moisture, thus resulting in an increase of thermal conductivity.

Table 5. Regression of Temperature and Moisture Content with Thermal Conductivity

\begin{tabular}{|c|c|c|}
\hline & Fitting Formulas & $R^{2}$ \\
\hline $\begin{array}{c}\text { Regression of moisture content } \\
\text { with thermal conductivity }\end{array}$ & $y=0.0026 x+0.1005$ & $R^{2}=0.9552$ \\
\hline $\begin{array}{c}\text { Regression of temperature with } \\
\text { thermal conductivity }\end{array}$ & $y=0.0004 x+0.108$ & $R^{2}=0.9524$ \\
\hline
\end{tabular}

Table 5 shows the relationship between the thermal conductivity of wood and temperature of the test specimens and the wood moisture content. The tested objects were the specimen group of SR that was immersed in distilled water for $12 \mathrm{~h}$ and the specimen group of ST that was immersed in distilled water for $24 \mathrm{~h}$. When the temperature remained constant, the thermal conductivity increased linearly with the moisture content of the wood. The slope of the thermal conductivity with increased temperature was remarkably lower than the slope of the thermal conductivity with increased moisture content. This indicated that the moisture content of wood played a key role in its thermal conductivity. This is consistent with the experimental conclusions of other wood species (Raznjevic 1995).

\section{Wood Deformation during Heat Transfer}

Figure 3 shows the dimensional deformation degree of air-dried Taxodium hybrid 'Zhongshanshan' wood specimens in the longitudinal, radial, and tangential directions at different heat transfer stages. During the period when the testing temperature was increased from $-10{ }^{\circ} \mathrm{C}$ to $30{ }^{\circ} \mathrm{C}$, the deformation caused repeated swelling-shrinkage cycles in the longitudinal, radial, and tangential directions. 


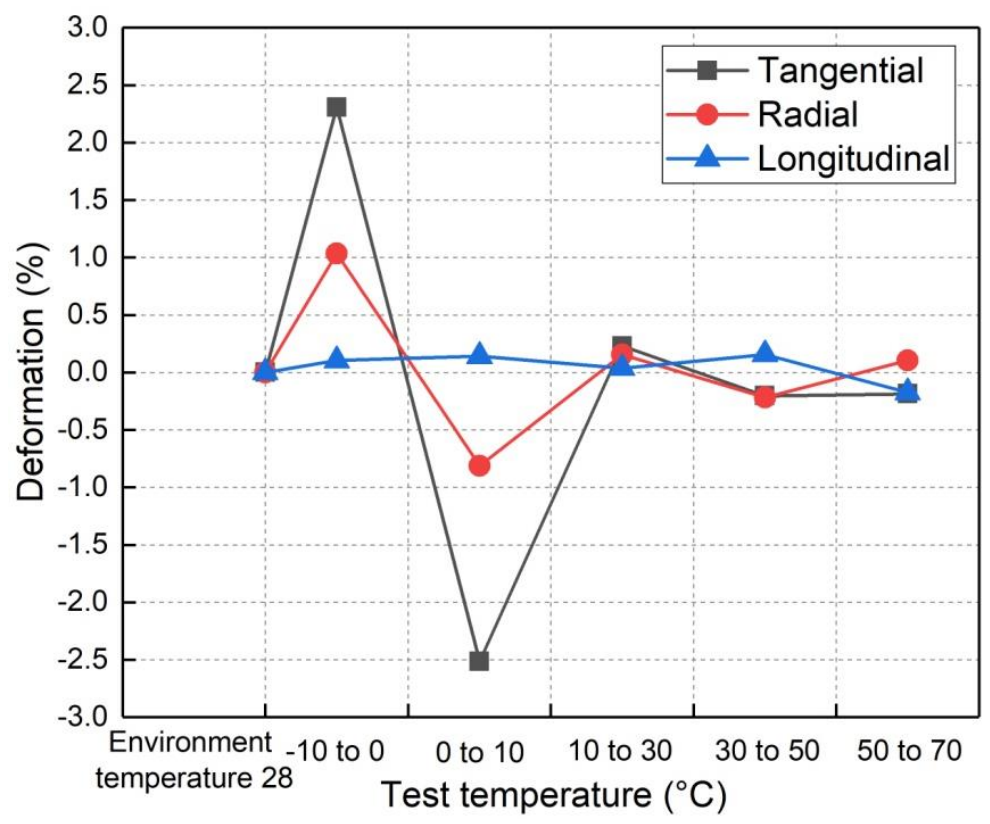

Fig. 3. Deformation of three directions of Taxodium hybrid 'Zhongshanshan' wood at different heat transfer stages

During the period when the testing temperature was increased from $-10{ }^{\circ} \mathrm{C}$ to $30{ }^{\circ} \mathrm{C}$, the longitudinal deformation was smallest, and the tangential deformation was largest (approximately twice that of the radial deformation). When the testing temperature was lower than $0{ }^{\circ} \mathrm{C}$, the water inside the wood cells formed ice crystals, which resulted in the swelling of the wood cells. Moreover, the ice on the cold plate absorbed heat and melted to water, thus causing an increase of the wood moisture content and an expansion of the overall dimensions of wood samples. As the temperature increased, the wood shrank because the ice crystals melted and the water in the cell walls moved to the cell cavity (Ilic 1995).

\section{Wood deformation at a testing temperature of $10^{\circ} \mathrm{C}$ to $70^{\circ} \mathrm{C}$}

When the testing temperature ranged from $10^{\circ} \mathrm{C}$ to $70{ }^{\circ} \mathrm{C}$, the moisture content of wood was $11 \%$ to $13 \%$, and the deformation of the wood in the longitudinal, radial, and tangential directions was less than $1 \%$. However, the accuracy of the Vernier caliper is only $0.02 \mathrm{~mm}$. The deformation was too small, the measurement error of the Vernier caliper may lead to inaccurate data (Fig. 3). Therefore, in the subsequent experiments, the wood deformation was recorded using a resistive strain gauge. The results showed that the maximum deformation of wood was approximately $5000 \mu \varepsilon$.

Figure 4 shows the deformations of the air-dried specimen group of HT in the longitudinal, radial, and tangential directions measured by the resistance strain gauge at a testing temperature of $10{ }^{\circ} \mathrm{C}$ to $70{ }^{\circ} \mathrm{C}$. When the testing temperature was $10{ }^{\circ} \mathrm{C}$ to $30{ }^{\circ} \mathrm{C}$, no obvious wood deformation was observed in the longitudinal, radial, and tangential directions. As the testing temperature was gradually increased from $30{ }^{\circ} \mathrm{C}$ to $50{ }^{\circ} \mathrm{C}$, the wood generated tensile stress in the radial and tangential directions as its dimensions increased. The tangential deformation was approximately twice that of the radial deformation. When the testing temperature was between $50{ }^{\circ} \mathrm{C}$ and $70{ }^{\circ} \mathrm{C}$, the radial and tangential dimensions of the wood remained unchanged. 


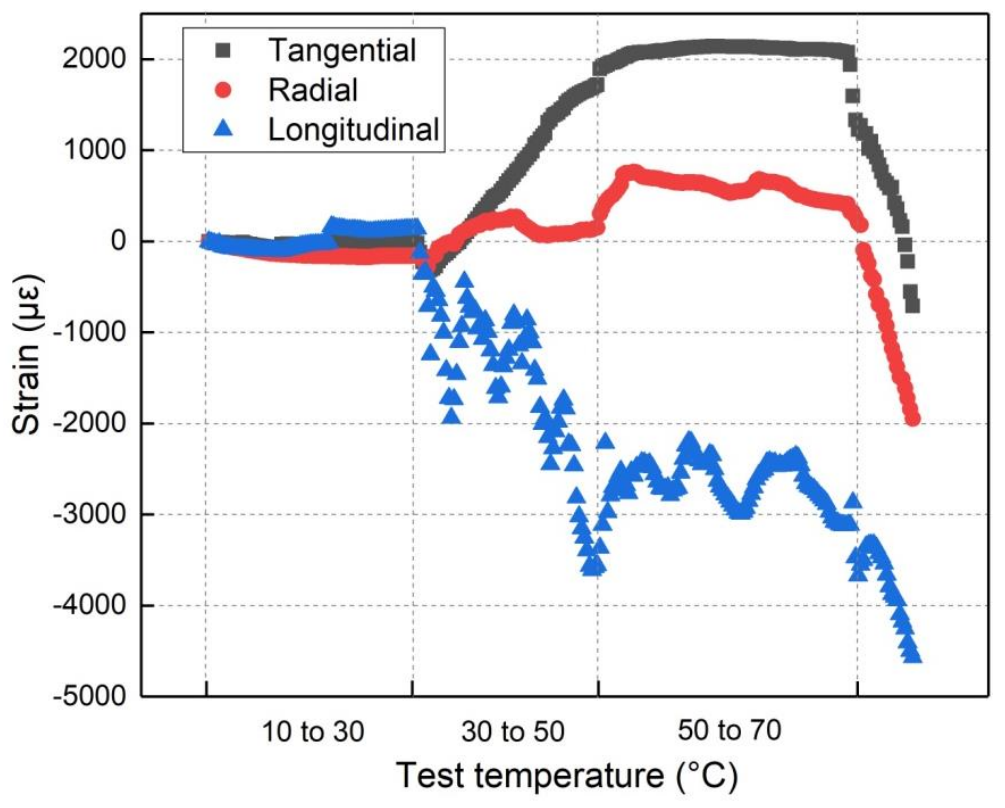

Fig. 4. Strain gauge data

When the testing temperature ranged from $30{ }^{\circ} \mathrm{C}$ to $70{ }^{\circ} \mathrm{C}$, pressure stress was generated in the longitudinal direction. The Poisson's ratio of wood is larger than that of other materials, and the wood is an orthotropic material that follows the trend:

$$
\mu \mathrm{RT}>\mu \mathrm{TL}>\mu \mathrm{RL}
$$

The thermal expansion of wood in the radial direction was generally smaller than the tangential direction. It was related to the fact that the restriction of wood rays and the cell wall thickness was different in radial and tangential direction. Due to the Poisson effect, tensile stress was generated when the wood swelled in the radial and tangential directions, and pressure stress was generated when the wood swelled in the longitudinal direction. The wood continued to shrink in the longitudinal direction, and the dimensional change caused by this shrinkage was comparable to the dimensional change caused by the swelling in its radial and tangential directions (Kumpenza et al. 2018).

When the testing temperature continued to increase, the moisture content of the wood continued to decrease. The longitudinal direction of the wood shrunk further, and the radial and tangential directions of wood gradually returned to their original dimensions. Pressure stress began to emerge in the radial and tangential directions and the whole wood specimen began to shrink.

\section{CONCLUSIONS}

1. The thermal conductivity of wood was independent of its source (heartwood or sapwood) and was related to its direction (radial or tangential). For Taxodium hybrid 'Zhongshanshan' wood, the tangential thermal conductivity was higher than the radial thermal conductivity. When the moisture content was $12 \%$ and the heat transfer 
temperature was $30{ }^{\circ} \mathrm{C}$, Taxodium hybrid 'Zhongshanshan' wood had an average thermal conductivity of $0.1257 \mathrm{~W} /(\mathrm{m} \cdot \mathrm{K})$.

2. When the temperature of the Taxodium hybrid 'Zhongshanshan' wood was higher than $0{ }^{\circ} \mathrm{C}$, the thermal conductivity of wood increased linearly with both the temperature and the moisture content of wood, and the moisture content played a key role in the thermal conductivity of the wood.

3. When the testing temperature was increased from $-10{ }^{\circ} \mathrm{C}$ to $30{ }^{\circ} \mathrm{C}$, the deformation featured repeated swelling-shrinkage cycles in the longitudinal, radial, and tangential directions. When the testing temperature ranged from $30{ }^{\circ} \mathrm{C}$ to $70{ }^{\circ} \mathrm{C}$, no obvious deformation was observed.

4. When the testing temperature was $30{ }^{\circ} \mathrm{C}$ to $70{ }^{\circ} \mathrm{C}$, the moisture content of the wood was largely constant. Tensile stress was generated in the radial and tangential directions as the wood dimensions increased. Due to the Poisson effect, compressive stress was generated in the longitudinal direction and shrinkage occurred. Dimensional swelling in the radial and tangential directions was equal to the dimensional shrinkage in the longitudinal direction.

5. During the heat transfer process, the dimensional change of Taxodium hybrid 'Zhongshanshan' wood was greatly influenced by the moisture content and was less affected by the heat transfer temperature.

\section{ACKNOWLEDGEMENTS}

This research was supported by the Jiang Su agricultural Science and Technology Innovation fund (Grant No. CX(16)1005) and the Plant Germplasm Resources Innovation Project of Strategic Bioresources Service Network of the Chinese Academy of Sciences (Grant No. ZSZC-009). The financial support received is gratefully acknowledged.

\section{REFERENCES CITED}

ASTM C 518 (2017). "Standard test method for steady-state thermal transmission properties by means of the heat flow meter apparatus," ASTM International, West Conshohocken, PA, USA

Dündar, T., Kurt, Ş., As, N., and Uysal, B. (2012). "Nondestructive evaluation of wood strength using thermal conductivity," BioResources 7(3), 3306-3316. DOI: 10.15376/biores.7.3.3306-3316

Gu, H. M., and Hunt, J. M. (2007). "Two-dimensional finite element heat transfer model of softwood. Part III," Wood and Fiber Science 39(1), 159-166.

Gu, H. M., and Hunt, J. M. (2006). "Two-dimensional finite element heat transfer model of softwood. Part II," Wood and Fiber Science 38(4), 599-608.

Gu, H. M., and Zinksharp, A. (2005). "Geometric model for softwood transverse thermal conductivity. Part I," Wood and Fiber Science 37(4), 699-711.

Hua, J. F., Han, L. W., Gu, C. S., and Yin, Y. L. (2017). "Morpho-anatomical and photosynthetic responses of Taxodium hybrid 'Zhongshanshan' 406 to prolonged flooding," Flora - Morphology, Distribution, Functional Ecology of Plants 231(6), 
29-37. DOI: 10.1016/j.flora.2017.04.007

Ilic, J. (1995). "Advantages of prefreezing for reducing shrinkage-related degrade in eucalypts: General considerations and review of the literature," Wood Science and Technology 29(4), 277-285. DOI: 10.1007/BF00202087

Kumpenza, C., Matz, P., Halbauer, P., Grabner, M., Steiner, G., Feist, F., and Muller, U. (2018). "Measuring Poisson's ratio: Mechanical characterization of spruce wood by means of non-contact optical gauging techniques," Wood Science and Technology 52(6), 1451-1471. DOI: 10.1007/s00226-018-1045-7

MacLean, J. D. (1941). "Thermal conductivity of wood," Heating, Piping and Air Conditioning 13(6), 380-391.

Saastamoinen, J., and Richard, J.-R. (1996). "Simultaneous drying and pyrolysis of solid fuel particles," Combustion and Flame 106(3), 288-300. DOI: 10.1016/00102180(96)00001-6

Şahin Kol, H. (2009). "Thermal and dielectric properties of pine wood in the transverse direction," BioResources 4(4), 1663-1669. DOI: 10.15376/biores.4.4.1663-1669

Sasthiryar, S., Abdul Khalil, H. P. S., Ahmad, Z. A., Nazrul Islam, M., Dungani, R., and Fizree, H. M. (2014). "Carbon nanofiller-enhanced ceramic composites: Thermal and electrical studies," BioResources 9(2), 3143-3151. DOI: 10.15376/biores.9.2.31433151

Shi, Q., Yin, Y. L., Wang, Z. Q., Fan, W. C., and Hua, J. F. (2016). "Physiological acclimation of Taxodium hybrid 'Zhongshanshan 118' plants to short-term drought stress and recovery," HortScience 51(9), 1159-1166. DOI: 10.21273/HORTSCI10997-16

Steinhagen, H. P. (1977). Thermal Conductive Properties of Wood, Green or Dry, From $40^{\circ}$ to $+100^{\circ} \mathrm{C}$ : A Literature Review (GTR/FPL-09), U.S. Department of Agriculture Forest Service, Madison, WI, USA.

Suleiman, B. M., Larfeldt, T., and Leckner, B. (1999). "Thermal conductivity and diffusivity of wood," Wood Science and Technology 33(6), 465-473. DOI: $10.1007 / \mathrm{s} 002260050130$

Thunman, H., and Leckner, B. (2002). "Thermal conductivity of wood models for different stages of combustion," Biomass and Bioenergy 23(1), 47-54. DOI: 10.1016/S0961-9534(02)00031-4

Raznjevic, K. (1995). "Handbook of thermodynamic tables," in: Thermal Conductivity $\lambda$ of Building Materials, Begell House, New York, NY, USA, pp. 29-36.

Zhu, Y. H., Wang, X. Z., Zhang, Y. L., and Pan, B. (2019). "Cell deformation of Taxodium hybrid 'Zhongshanshan' wood during the drying process," BioResources 14(3), 62196230. DOI: 10.15376/biores.14.3.6219-6230

Article submitted: November 27, 2019; Peer review completed: February 13, 2020; Revised version received: February 17, 2020; Accepted: February 23, 2020; Published: February 25, 2020.

DOI: 10.15376/biores.15.2.2645-2655 